\title{
Prevalence of rheumatic heart disease in Senegalese school children: a clinical and echocardiographic screening
}

\author{
Aliou Alassane Ngaïdé, ${ }^{1}$ Alassane Mbaye, ${ }^{1}$ Adama Kane, ${ }^{2,3}$ \\ Mouhamadou Bamba Ndiaye, ${ }^{2}$ Modou Jobe, ${ }^{2,4}$ Malick Bodian, ${ }^{2}$ Momar Dioum, ${ }^{2}$ \\ Simon Antoine Sarr, ${ }^{2}$ Fatou Aw, ${ }^{2}$ Prisca Sede Mbakop, ${ }^{1}$ Fatimata Gatta Ba, ${ }^{2}$ \\ Ngoné Diaba Gaye, ${ }^{1}$ Alioune Tabane, ${ }^{2}$ Mamadou Bassirou Bah, ${ }^{2}$ Sarah Mouna Coly, ${ }^{2}$ \\ Dior Diagne, ${ }^{1}$ Bouna Diack, ${ }^{1}$ Maboury Diao, ${ }^{2}$ Abdoul Kane ${ }^{1}$
}

\begin{abstract}
${ }^{1}$ Cardiology Department of Grand Yoff General Hospital, Dakar, Senegal

${ }^{2}$ Cardiology Department of Aristide Le Dantec Teaching Hospital, Dakar, Senegal

${ }^{3}$ Unités de Formation et de Recherche (UFR), Santé

Université Gaston Berger de Saint-Louis, Saint Louis, Sénégal

${ }^{4}$ Medical Research Council Unit, Atlantic Boulevard, Fajara, The Gambia
\end{abstract}

\section{Correspondence to} Dr Modou Jobe, Service de Cardiologie, CHU Aristide Le Dantec, Dakar BP 3001; Senegal; modoujobe@gmail. com

Received 31 July 2015 Revised 1 October 2015 Accepted 3 November 2015

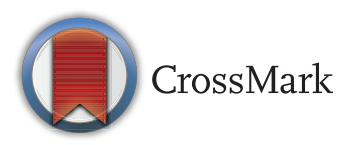

\footnotetext{
To cite: Ngaïdé $A A$, Mbaye $A$, Kane $A$, et al. Heart Asia 2015;7:40-45. doi:10.1136/heartasia-2015010664
}

\begin{abstract}
Objective To study the prevalence of rheumatic heart disease (RHD) in schools (locally referred to as 'daaras') located in the city of Dakar and its suburbs using both clinical examination and echocardiography.

Methods This is a cross-sectional study conducted from 9 August to 24 December 2011 involving 2019 pupils, aged between 5 and 18 years selected from the 16 'daaras' of the Academic Inspectorate (Inspection $d^{\prime}$ Académie) of the city of Dakar and its suburbs. Anamnestic, clinical and echocardiographic data were collected and entered into a questionnaire designed for the study. The World Heart Federation criteria for echocardiographic diagnosis were used to diagnose RHD. $p<0.05$ was considered statistically significant in bivariate analysis.
\end{abstract}

Results About $60.1 \%$ of the pupils were men and the mean age was $9.7 \pm 3.3$ years. 10 cases of definite RHD were detected, prevalence being 4.96 per $1000(95 \% \mathrm{Cl}$ 2.4 to 9.1). This prevalence was five times higher with echocardiographic screening compared with clinical screening. 23 cases (11.4 per 1000) of borderline forms were detected. The populations at risk of definite RHD identified in our study were children over 14 years $(p<0.001)$, those with recurrent sore throat $(p=0.003)$ and those residing in the suburbs of the city of Dakar $(p<0.001)$.

Conclusion Our study shows a relatively high prevalence of RHD. Reducing its prevalence should focus on the implementation of appropriate policies, targeting at-risk populations and focusing on raising awareness and early detection.

\section{INTRODUCTION}

Rheumatic heart disease (RHD), a sequela of rheumatic fever, is a major cardiovascular disease in children and young adults in most low/ middle-income countries. ${ }^{1}{ }^{2}$ Most epidemiological studies have estimated the prevalence of RHD to about $1-5$ per 1000 . Since the first report of echocardiography as a potential screening tool, ${ }^{3}$ surveys were carried out in Mozambique, and subsequently in Uganda and in Senegal. ${ }^{1}$ 4-6 All these studies demonstrated that echocardiography detects a significant additional number of children with clinically silent RHD, estimated to 7.5-51.6 per 1000 children.

Although echocardiography may prove to be a valuable tool in detecting RHD cases at an early stage, fundamental issues remain to be addressed. ${ }^{7} 8$ Echocardiographic detection of morphologically abnormal valves or significant valvular regurgitation does not guarantee later progression to advanced valvular disease nor has the clinical effectiveness of secondary prophylaxis in this population been proven. A first step towards the assessment of subclinical RHD has been taken through the standardisation of echocardiographic criteria under the auspices of the World Heart Federation (WHF). ${ }^{9}$

Further data are needed to assess the socioeconomic impact of RHD in sub-Saharan countries. RHD is associated with a high morbidity due to scarcity of prevention programmes across most sub-Saharan African countries, which may strongly impact on social, educational and economic issues. Hospital-based studies recently reported that RHD accounts for $6.6 \%-34.0 \%$ of cardiovascular disease-related hospital admissions or echocardiographic examinations performed in institutions across Africa. ${ }^{10-12}$

The objective of this study was to investigate the prevalence of RHD in schools locally known as 'daaras' in the city of Dakar and its suburbs using clinical and echocardiographic criteria as per the new guidelines of the WHF.

\section{METHODS}

This work was done in collaboration with the Health Inspectorate of Schools (Inspection Médicale des Ecoles) of Dakar, after authorisation and approval from the Academic Inspectorate of Dakar. Prior to visiting the respective schools for the screening exercise, a message was sent to the respective school administrations who informed the teachers as well as parents. Meetings were held in the respective schools during which the research team explained the details of the study and invited questions to clarify any misunderstanding. Verbal consent, since no intervention was involved, was obtained from all parents.

It was a cross-sectional study conducted from 9 August to 24 December 2011 and included pupils 
of ages between 5 and 18, from 16 schools in the city of Dakar and its suburbs. All the pupils attending the 16 schools, apart from the 1 with a large population, were included. In this particular school, we randomly chose half of the classes, which was determined by simple drawing of lots. Pupils who refused to be examined were excluded from the study. The equipments used were a stethoscope (Littmann classic), an examination bed, a portable device echocardiography (Sonosite MicroMax) equipped with probes of 3.5 and $5 \mathrm{MHz}$, with pulsed and continuous waves, colour and tissue Doppler facilities. The questionnaire was critically examined and validated by a group of four experienced cardiologists and an epidemiologist.

The schools were boarding and most had an infirmary. Clinical details, such as sore throat, joint pains, were obtained from their case notes that were kept at the school's infirmary. Where this was not available, the question was asked to the child (in their local language), to the teachers and in some cases their parents when they were present. Data collected were biodata (full name, age, sex, area of residence and occupation of parents or guardians) and history (recurrent sore throat and the treatment administered and duration, arthritis or arthralgia, heart disease or other non-cardiac diseases: sickle cell anaemia, asthma, poliomyelitis, diabetes).

The pupils were examined with their shirts removed. Physical examination consisted of systematic cardiac auscultation, in the supine, left lateral and sitting positions. We also looked for signs of rheumatic fever. In addition, the pupils had ear-nose-throat and dental review.

A transthoracic Doppler echocardiography focusing on the heart valves was conducted in all pupils included in the study. We studied valvular opening and thickness, looked for regurgitation or the presence of vegetation and valvular calcification, and also studied the subvalvular apparatus. The WHF criteria for diagnosis ${ }^{13}$ were used to diagnose RHD (box 1).

Certified cardiologists performed physical examination and echocardiography. Images suspected of being pathological were recorded in the device memory for later review by three independent cardiologists who were not informed of the clinical data. For the diagnosis of RHD to be made, the different criteria were to be identified by at least two of three independent observers.

The pupils for whom cardiac auscultation did not find abnormalities were considered to have had a normal physical examination. Those in whom a murmur was detected clinically and in whom RHD was confirmed by echocardiography were classified as clinically detected (figure 1 ).

All data collected were entered into Epi data and analysed using SPSS (V.16.0; SPSS, Chicago, Illinois, USA) and Microsoft Excel. Qualitative variables were written as percentage and the quantitative variables as averages and SDs. The different frequencies were compared using the $\chi^{2}$ test and Fisher's test. A $\mathrm{p}$ value of $<0.05$ was considered to be statistically significant.

\section{RESULTS}

Among the 2019 pupils included in the study, 1213 (60.1\%) were boys and 806 (39.9\%) were girls and were aged between 5 and 18 years. The mean age was $9.7 \pm 3.3$ years. Most of the pupils included in our study were living in the suburbs of Dakar $(83.5 \%)$. A total of $312(15.4 \%)$ had a history of recurrent sore throat. In this population, three $(0.05 \%)$ had a tonsillectomy. Only 131 pupils (22.4\%) received oral antibiotics for at least
Box 1 World Heart Federation's criteria for

echocardiographic diagnosis of RHD

Definite RHD (either A, B, C or D)

A. Pathological MR and at least two morphological features of RHD of the MV

B. MS mean gradient $\geq 4 \mathrm{~mm} \mathrm{Hg}$ (NB-exclude congenital MV anomalies)

C. Pathological $A R$ and at least two morphological features of RHD of the AV(NB-exclude bicuspid AV and dilated aortic root)

D. Borderline disease of both the aortic and MVs as defined below

Borderline RHD (either A, B or C)

A. At least two morphological features of RHD of the MV without pathological MR or MS

B. Pathological MR

C. Pathological AR

Normal echocardiographic findings (all of $A, B, C$ and D)

A. MR that does not meet all four Doppler echocardiographic criteria (physiological MR)

B. AR that does meet all four Doppler echocardiographic criteria (physiological AR)

C. An isolated morphological feature of RHD of the MV (eg, valvular thickening) without any associated pathological stenosis or regurgitation

D. Morphological feature of RHD of the AV (eg, valvular thickening) without any associated pathological stenosis or regurgitation

Criteria for Pathological Regurgitation

Pathological mitral regurgitation (all four Doppler

echocardiographic criteria must be met)

- Seen in two views

- In at least one view, jet length $\geq 2 \mathrm{~cm}$, measured from the vena contracta to the last pixel of regurgitant colour (blue or red)

- Velocity $\geq 3 \mathrm{~m} / \mathrm{s}$ for one complete envelope

- Pan-systolic jet in at least one envelope

Pathological AR (all four Doppler echocardiographic criteria must be met)

- Seen in two views

- In at least one view, jet length $\geq 1 \mathrm{~cm}$ measured from the vena contracta to the last pixel of regurgitant colour (blue or red)

- Velocity $\geq 3 \mathrm{~m} / \mathrm{s}$ in early diastole

- Pan-diastolic jet in at least one envelope

Morphological Features of RHD

Features in the MV

- AMVL thickening $\geq 3 \mathrm{~mm}$ (age-specific)

- Chordal thickening

- Restricted leaflet motion

- Excessive leaflet tip motion during systole

Features in the AV

- Irregular or focal thickening

- Coaptation defect

- Restricted leaflet motion

- Prolapse

$A M V L$, anterior mitral valve leaflet; $A R$, aortic regurgitation; $A V$, aortic valve; $M R$, mitral regurgitation; $M S$, mitral stenosis; MV, mitral valve; RHD, rheumatic heart disease. 
Figure 1 Diagnostic schema of cases of definite rheumatic heart disease.

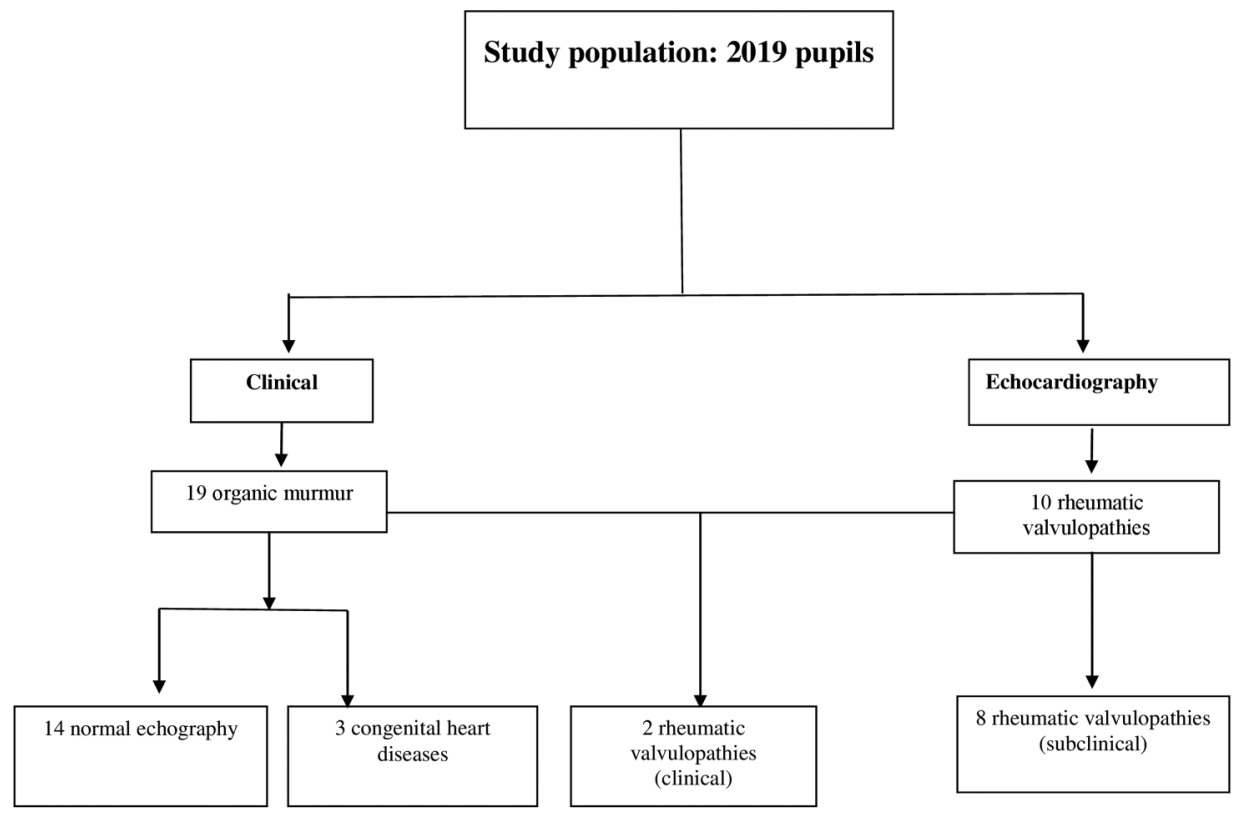

7 days. Twenty-seven pupils (1.3\%) had pain and/or joint swelling. History was mostly dominated by dental disease $(3.7 \%)$.

We detected 10 cases of definite RHD (whose characteristics are presented in tables 1 and 2), and an overall prevalence of 4.95 per 1000 (95\% CI 2.4 to 9.1). This prevalence was five times higher with echocardiographic screening than with clinical screening (1 in 1000) (table 3). All cases of definite RHD were asymptomatic. Among the 10 cases of RHD, we found 80\% (eight cases) with pure mitral regurgitation and $20 \%$ with aortic regurgitation.

The prevalence of definite RHD in girls (5 per 1000) was identical to that in boys (4.9 per 1000) with $p=1.000$. It was higher in children aged 14 years and above (6.2 per 1000) than in those aged less than 14 years (4.1 per 1000). The difference

Table 1 Bivariate analysis of demographic and clinical characteristics of definite RHD cases

\begin{tabular}{|c|c|c|c|}
\hline $\begin{array}{l}\text { Dependent } \\
\text { variables/definite RHD }\end{array}$ & No. & $\begin{array}{l}\text { Prevalence } \\
\text { (per 1000) }\end{array}$ & p Value \\
\hline \multicolumn{4}{|l|}{ Age group } \\
\hline$<14$ years & 5 & 4.1 & \multirow[t]{2}{*}{$<0.001$} \\
\hline$\geq 14$ years & 5 & 6.2 & \\
\hline \multicolumn{4}{|l|}{ Sex } \\
\hline Male & 6 & 4.9 & \multirow{2}{*}{$\begin{array}{l}\text { Not } \\
\text { significant }\end{array}$} \\
\hline Female & 4 & 5 & \\
\hline \multicolumn{4}{|l|}{ Place of residence } \\
\hline Dakar-centre & 0 & 0 & \multirow[t]{2}{*}{$<0.001$} \\
\hline Dakar-suburb & 10 & 5.9 & \\
\hline \multicolumn{4}{|l|}{ Socio-economic status } \\
\hline Low & 4 & 3.8 & \multirow{2}{*}{$\begin{array}{l}\text { Not } \\
\text { significant }\end{array}$} \\
\hline High & 6 & 6.1 & \\
\hline \multicolumn{4}{|l|}{ Recurrent sore throat } \\
\hline Rare & 5 & 2.5 & \multirow[t]{2}{*}{0.003} \\
\hline Frequent & 5 & 15.8 & \\
\hline \multicolumn{4}{|c|}{ History of arthritis and/or arthralgia } \\
\hline Present & 0 & 0 & \multirow[t]{2}{*}{$<0.001$} \\
\hline Absent & 10 & 5 & \\
\hline
\end{tabular}

between these two prevalence rates was statistically significant $(p<0.001)$. Cases of definite RHD were only found among pupils residing in the suburbs of Dakar. The prevalence of definite RHD was lower in pupils from good socio-economic background than in children from average to low socio-economic status $(p=0.5)$ and was significantly higher among pupils who had a history of repeated sore throat (OR 5.4, 95\% CI 1.6 to $18.9, \mathrm{p}<0.003)$. In addition, among the 10 cases with detected RHD, 5 had repeated episodes of sore throat, and only 1 received appropriate antibiotic treatment. No case of definite RHD was found in pupils who presented with a history of arthritis or arthralgia. In addition, we found 23 cases of borderline forms, a prevalence of 11.5 per 1000 .

\section{DISCUSSION}

This was the second school survey in Senegal using clinical and echocardiographic criteria. However, this study was conducted in Koranic schools locally known as 'daaras' which are crowded, usually boarding schools and commonly insalubrious compared with conventional schools. Many of these local schools operate independent of the Academic Inspectorate of Dakar. A survey in 2009 by the Inspectorate found 988 schools not registered, with a total population of 23321 pupils including 18402 boys (78.9\%) and 4919 girls (21.1\%). Our study, however, included only the 16 schools registered under the Inspectorate.

Of 2019 students in our study, no case of definite RHD detection was previously known. In Mozambique, ${ }^{1}$ one of the students had a known RHD. The prevalence rate of RHD by echocardiographic screening was 4.95 per 1000 and therefore five times higher than by clinical screening (1 per 1000). A similar observation was made in recent studies in Senegal, ${ }^{14}$ Cambodia and Mozambique. ${ }^{1}$ These studies found 5-10 times higher prevalence rates, being 1.5, 2.2 and 2.3 per 1000, respectively, with clinical screening compared with 7.5, 21.5 and 30.4 per 1000 with echocardiographic screening. The lower prevalence in our study may be explained among other things, by the lower age of the pupils compared with these studies. Another reason for the lower prevalence was the use of the more specific WHF standardised criteria, which were not available for those studies. However, Colquhoun et $a l^{15}$ in a 
Table 2 Characteristics of definite RHD cases

\begin{tabular}{|c|c|c|c|c|c|c|}
\hline Patient & Age & Sex & Residence & $\begin{array}{l}\text { Frequency of sore throat } \\
\text { and treatment }\end{array}$ & Auscultation & Echocardiography \\
\hline 1 & 09 years & $\mathrm{M}$ & Dakar-suburb & Rarely & Normal & $\begin{array}{l}\text { Mitral regurgitation seen in four views with a jet length of }>2 \mathrm{~cm} \text {, } \\
\text { maximal velocity of } 3.9 \mathrm{~m} / \mathrm{s} \text { and a pan-systolic jet } \\
\text { Chordal thickening and of the AMVL measuring } 6.5 \mathrm{~mm} \\
\text { Conclusion: rheumatic mitral insufficiency }\end{array}$ \\
\hline 2 & 14 years & $\mathrm{M}$ & Dakar-suburb & Rarely & Normal & $\begin{array}{l}\text { Mitral regurgitation seen in two views with a jet length of }>2 \mathrm{~cm} \text {, } \\
\text { maximal velocity of } 3.5 \mathrm{~m} / \mathrm{s} \text { and a pan-systolic jet } \\
\text { Chordal thickening and of the AMVL } \\
\text { Conclusion: rheumatic mitral insufficiency }\end{array}$ \\
\hline 3 & 11 years & $\mathrm{M}$ & Dakar-suburb & Rarely & Normal & $\begin{array}{l}\text { Aortic regurgitation seen in two views with a jet length of }>1.13 \mathrm{~cm} \text {, } \\
\text { maximal velocity in early diastole of } 3.07 \mathrm{~m} / \mathrm{s} \text { and a pan-diastolic jet } \\
\text { Coaptation defect and thickening of right anterior aortic cusp, chordal } \\
\text { thickening and that of the AMVL measuring } 5.6 \mathrm{~mm} \\
\text { Conclusion: rheumatic aortic insufficiency associated with a borderline } \\
\text { disease of MV }\end{array}$ \\
\hline 4 & 12 years & $\mathrm{M}$ & Dakar-suburb & Rarely & $\begin{array}{l}\text { Signs of mitral } \\
\text { insufficiency }\end{array}$ & $\begin{array}{l}\text { Mitral regurgitation seen in all views with a jet length of }>2.7 \mathrm{~cm} \text {, } \\
\text { maximal velocity of } 4.9 \mathrm{~m} / \mathrm{s} \text { and a pan-systolic jet } \\
\text { Chordal thickening and of the AMVL measuring } 7.7 \mathrm{~mm} \\
\text { Conclusion: rheumatic mitral insufficiency }\end{array}$ \\
\hline 5 & 14 years & $\mathrm{M}$ & Dakar-suburb & Rarely & $\begin{array}{l}\text { Signs of mitral } \\
\text { insufficiency }\end{array}$ & $\begin{array}{l}\text { Mitral regurgitation seen in two views with a jet length of }>2.85 \mathrm{~cm} \text {, } \\
\text { maximal velocity of } 3 \mathrm{~m} / \mathrm{s} \text { and a pan-systolic jet } \\
\text { Chordal thickening and of the AMVL } \\
\text { Conclusion: rheumatic mitral insufficiency }\end{array}$ \\
\hline 6 & 14 years & $\mathrm{F}$ & Dakar-suburb & $\begin{array}{l}\text { Once/year; never given } \\
\text { antibiotic treatment }\end{array}$ & Normal & $\begin{array}{l}\text { Aortic regurgitation seen in two views with a jet length of } 2.85 \mathrm{~cm} \text {, } \\
\text { maximal velocity in early diastole of }>3 \mathrm{~m} / \mathrm{s} \text { and a pan-diastolic jet } \\
\text { Irregular thickening of right anterior and posterior cusps, restrictive } \\
\text { movements of aortic cusps } \\
\text { Conclusion: rheumatic aortic insufficiency }\end{array}$ \\
\hline 7 & 14 years & $\mathrm{F}$ & Dakar-suburb & $\begin{array}{l}\text { Twice/year ; oral antibiotics } \\
\text { given for } 10 \text { days }\end{array}$ & Normal & $\begin{array}{l}\text { Mitral regurgitation seen in two views with a jet length of } 2.2 \mathrm{~cm} \text {, } \\
\text { maximal velocity of } 4.12 \mathrm{~m} / \mathrm{s} \text { and a pan-systolic jet } \\
\text { Chordal thickening and of the AMVL } \\
\text { Conclusion: rheumatic mitral insufficiency }\end{array}$ \\
\hline 8 & 14 years & $\mathrm{F}$ & Dakar-suburb & Rarely & Normal & $\begin{array}{l}\text { Mitral regurgitation seen in two views with a jet length of } 3.13 \mathrm{~cm} \text {, } \\
\text { maximal velocity of }>3 \mathrm{~m} / \mathrm{s} \text { and a pan-systolic jet } \\
\text { Chordal thickening and of the AMVL } \\
\text { Conclusion: rheumatic mitral insufficiency }\end{array}$ \\
\hline 9 & 12 years & $\mathrm{F}$ & Dakar-suburb & $\begin{array}{l}\text { Once/year } \\
\text { Oral antibiotics given } \\
\text { for } 3 \text { days }\end{array}$ & Normal & $\begin{array}{l}\text { Mitral regurgitation seen in three views with a jet length of } 2.09 \mathrm{~cm} \text {, } \\
\text { maximal velocity of } 4.3 \mathrm{~m} / \mathrm{s} \text { and a pan-systolic jet } \\
\text { Conclusion: rheumatic mitral insufficiency }\end{array}$ \\
\hline 10 & 06 years & $\mathrm{M}$ & Dakar-suburb & $\begin{array}{l}\text { Twice/year; never received } \\
\text { antibiotic treatment }\end{array}$ & Normal & $\begin{array}{l}\text { Mitral regurgitation seen in two views with a jet length of } 2 \mathrm{~cm} \text {, } \\
\text { maximal velocity of }>3 \mathrm{~m} / \mathrm{s} \text { and a pan-systolic jet } \\
\text { Chordal thickening and of the AMVL } \\
\text { Conclusion: rheumatic mitral insufficiency }\end{array}$ \\
\hline
\end{tabular}

$A M V L$, anterior mitral valve leaflet; $F$, female; $M$, male; MV, mitral valve; RHD, rheumatic heart disease.

study in Fiji including school children of age 5-14 years and using the WHF criteria found a prevalence of 10.8 cases per 1000 , higher than in our study.

The prevalence we obtained is about twice the WHO estimates in 2003 for Senegal and the sub-Saharan African region. Indeed, the WHO estimated the average prevalence rate of

Table 3 Prevalence of rheumatic valvular heart disease based on diagnostic criteria $(n=2019)$

\begin{tabular}{lcll}
\hline Diagnostic criteria & No. & $\begin{array}{l}\text { Prevalence per } \\
1000(95 \% \mathrm{Cl})\end{array}$ & $\begin{array}{l}\mathrm{p} \\
\text { Value }\end{array}$ \\
\hline $\begin{array}{l}\text { Clinical diagnosis with echocardiographic } \\
\text { confirmation }\end{array}$ & 2 & 0.99 & \\
$\begin{array}{l}\text { Echocardiographic diagnosis with normal } \\
\text { clinical examination }\end{array}$ & 8 & 3.96 & $<0.03$ \\
\begin{tabular}{l} 
Total \\
\hline
\end{tabular} & 10 & $4.95(2.4$ to 9.1) & \\
\hline
\end{tabular}

RHD at 3 per 1000 for children aged between 5 and 14 years in sub-Saharan Africa. ${ }^{16}$ These estimates took into account a different age range to our study and did not take into account the use of echocardiography.

Furthermore, we found a high prevalence of borderline forms (11.5 per 1000). These forms require follow-up and prophylaxis with the current state of scientific knowledge is not indicated.

The prevalence observed in our study is similar to that of many African series ${ }^{1} 1718$ estimated at about $1-5$ per 1000 . On the other hand, Sadiq et $a l^{19}$ in Lahore found a higher prevalence than in our study (21.9 per 1000).

Of the 10 cases of RHD, there were $8(80 \%)$ with pure mitral regurgitation and $2(20 \%)$ with aortic regurgitation. These observations are similar to other studies, notably in Senegal ${ }^{14}$ where out of 15 cases, there were 14 (93.3\%) with mitral disease, including $8(53.3 \%)$ with pure mitral disease, and in Cambodia, where out of 79 cases of RHD, there were 61 $(77.2 \%)$ with pure mitral disease. Also, mitral disease was found in $87.3 \%$ of cases in Cambodia and in $98.4 \%$ of cases in 
Mozambique. ${ }^{1}$ These observations highlight the frequency of mitral disease in RHD.

The prevalence of definite RHD in our study in girls (5 per 1000) was almost identical to that in boys (4.9 per 1000) $(p=1)$. However, predominance of RHD in female has been reported by other authors, especially in Mozambique ${ }^{1}$ where the difference to male was significant $(p=0.04)$. This was also confirmed in a similar study using the same criteria as in our study in Fiji (Colquhoun). The mean ages (11.7 \pm 1.7 years) and extremes (6 and 14 years) of cases of RHD in our study are lower than in similar studies. ${ }^{1}{ }^{14}$ The prevalence of definite RHD was more in children over 14 years of age than those aged less $(p<0.001)$. These observations are consistent with studies in Australian Aborigines, ${ }^{20}$ which suggested that the prevalence of RHD was higher in children of over 15 years of age. Also, Marijon et $\mathrm{al}^{1}$ in Mozambique found that the prevalence of subclinical RHD increases with age, from $2.4 \%$ for the age group 6-9 years to $4.1 \%$ for the group $12-17$ years $(p=0.04)$.

Low socio-economic status often described as risk factor is confirmed in our work. Indeed, the prevalence of RHD was significantly higher in children from low socio-economic background, than in children from average to higher socio-economic levels $(p<0.04)$. This prevalence was also significantly higher among pupils living in the suburbs of Dakar than in those living in the city $(p<0.04)$. Similar observations were made by Marijon et $a l^{1}$ in Mozambique where the prevalence of RHD was significantly higher among pupils attending suburban schools than in urban schools $(p=0.04)$.

Repeated episodes of sore throat were identified in our study as a predisposing factor to the occurrence of RHD. Indeed, the prevalence of definite RHD was significantly higher among pupils with repeated sore throat than in those without $(p=0.03)$. This is consistent with what was found by Kimbally-Kaky et $a l^{21}$ in Brazzaville where history of sore throat was identified in all children found with RHD. In this study, sore throat was not treated in seven out of eight cases. These observations emphasise the high frequency and poor therapeutic management of sore throat in children. A better understanding of reasons behind the difficulty of primary prevention has been recently carried out in Tanzania, emphasising the negligence of patients and also medical staff regarding the importance of consulting and treating sore throat. ${ }^{22}$ The poor management of cases of diagnosed RHD has also been highlighted in the Global Rheumatic Heart Disease Registry (The REMEDY study) where only $55 \%$ of patients were found to be receiving antibiotic treatment. $^{23}$

However, in our study, we did not find any correlation between the occurrence of RHD and history of arthritis and/or arthralgia because none of the 10 pupils affected reported joint symptoms. This can be explained by the lack of specificity of these symptoms, which can be found in other childhood diseases.

Our study had some limitations. It included only children attending local schools known as 'Daara' and may not be representative of the overall picture in more modern conventional schools. The study was conducted in Dakar, the capital of Senegal and may not be truly representative with the reality in more rural settings. The subjectivity of echo readings may be another limitation. To avoid potential bias, each echo was read by three independent echocardiographers and a diagnosis was made when the criteria were identified by at least two of the three.

\section{CONCLUSION}

This study shows a prevalence of RHD in schools in Dakar slightly higher than WHO estimates for Senegal and in
sub-Saharan Africa. The combined use of these diagnostic criteria has helped to refine the diagnostic criteria for RHD.

Sadly, RHD diagnosis in Africa is usually established at an advanced stage of the disease, when severe valve lesions become symptomatic, and significant intervention is indicated. ${ }^{24}$ Reducing the prevalence of RHD should be through the implementation of appropriate policies, targeting at-risk populations and focusing on awareness and early detection. Indeed, tonsillectomy and secondary antibiotic prophylaxis are cheap and effective ways to prevent its occurrence.

\section{Key messages}

\section{What is already known about this subject?}

Much of what is known about the prevalence of rheumatic heart disease (RHD) is derived from studies relying on cardiac auscultation. This is the second school-based survey in Senegal using echocardiography as a screening tool. The first survey carried out in conventional day schools found a prevalence rate of 1.5 per 1000 with clinical screening and 7.5 per 1000 with echocardiographic screening.

\section{What does this study add?}

This study was carried out in more traditional (as opposed to conventional) schools in Senegal which are crowded boarding school in school attendees of age between 5 and 18 years. Most other studies were limited to children. We found a high prevalence of confirmed RHD and a high number of borderline forms in asymptomatic individuals, which was higher at age 14 years and over.

How might this impact on clinical practice?

Screening programmes should be extended to older children and adolescents given the high prevalence in this age group found in our study.

Contributors AAN, AM, AdK, AK, MBN and MJ designed the study protocol, participated in the data collection and contributed in analysing the data and writing of the draft manuscript. MB, MD, SAS, FA and PSM oversaw the execution of the study, participated in data analysis and critically revised the manuscript for important intellectual content. FGB, NDG, AT and MBB participated in study design and in data analysis. SMC, DD, BD and MoD participated in statistical analysis and interpretation of results. All authors have read and approved the final version of the manuscript.

Competing interests None declared.

Ethics approval The study protocol was approved by the Research Committee of the Université Cheikh Anta Diop (Cheikh Anta Diop University) in Dakar, Senegal.

Provenance and peer review Not commissioned; externally peer reviewed. Competing interests None declared.

Provenance and peer review Not commissioned; externally peer reviewed.

\section{REFERENCES}

1 Marijon E, Ou P, Celermajer DS, et al. Prevalence of rheumatic heart disease detected by echocardiographic screening. N Engl J Med 2007;357:470-6.

2 Toure S, Balde MD, Balde OD, et al. Enquête sur les cardiopathies en milieu scolaire et universitaire à Conakry (Guinée). Cardiologie Tropicale 1992;18:205-10.

3 Anabwani GM, Bonhoeffer P. Prevalence of heart disease in school children in rural Kenya using colour-flow echocardiography. East Afr Med J 1996;73:215-17.

4 Beaton A, Okello E, Lwabi P, et al. Echocardiography screening for rheumatic heart disease in Ugandan schoolchildren. Circulation 2012;125:3127-32.

5 Grimaldi A, Ammirati E, Mirabel M, et al. Challenges of using ultrasounds for subclinical rheumatic heart disease screening. Int J cardiol 2013;167:3061. 
6 Kane A, Mirabel M, Touré K, et al. Echocardiographic screening for rheumatic heart disease: age matters. Int J Cardiol 2013;168:888-91.

7 Marijon E, Ou P, Celermajer DS, et al. Echocardiographic screening for rheumatic heart disease. Bull World Health Organ 2008;86:84.

8 Zühlke L, Mayosi BM. Echocardiographic screening for subclinical rheumatic heart disease remains a research tool pending studies of impact on prognosis. Curr Cardiol Rep 2013;15:343.

9 Reményi B, Wilson N, Steer A, et al. World Heart Federation criteria for echocardiographic diagnosis of rheumatic heart disease - an evidence-based guideline. Nat Rev Cardiol 2012;9:297-309.

10 Tchoumi JCT, Ambassa JC, Kingue S, et al. Occurrence, aetiology and challenges in the management of congestive heart failure in sub-Saharan Africa: experience of the Cardiac Centre in Shisong, Cameroon. Pan Afr Med J 2011:8:11.

11 Sani MU, Karaye KM, Borodo MM. Prevalence and pattern of rheumatic heart disease in the Nigerian savannah: an echocardiographic study. Cardiovasc J Afr 2007;18:295-9.

12 Ntusi NB, Mayosi BM. Epidemiology of heart failure in sub-Saharan Africa. Expert Rev Cardiovasc Ther 2009;7:169-80.

13 Reményi $B$, Nigel W, Andrew $S$, et al. World Heart Federation publishes first international guidelines for echocardiographic diagnosis of rheumatic heart disease. Circulation 2012:89:57-109.

14 Zourak I. Prévalence des valvulopathies rhumatismales en milieu scolaire à Dakar: Etude transversale basée sur le dépistage clinique et échocardiographique de 2004 éléves. Thèse Médecine Université Cheikh Anta Diop de Dakar, 2010 $n^{\circ} 108$.
15 Colquhoun SM, Kado JH, Remenyi B, et al. Echocardiographic screening in a resource poor setting: Borderline rheumatic heart disease could be a normal variant. Int J Cardiol 2014;173:284-9.

16 World Health Organization. Rheumatic fever and rheumatic heart disease: report of a WHO Study Group. WHO Technical Report Series No 764. Geneva: World Health Organization 1988.

17 Bassand JP, Bernard Y. Insuffisance aortique (ECN). http://www.besancon-cardio. org/cours/16-rm.php (accessed on 25 Jun 2015).

18 Wallace MR, Garst PD, Papademos TJ, et al. The return of acute rheumatic fever in young adults. JAMA 1989;262:2557-61.

19 Sadiq M, Islam K, Abid R, et al. Prevalence of rheumatic heart disease in school children of urban Lahore. Heart 2009;95:353-7.

20 Carapetis JR, Currie BJ, Mathews JD. Cumulative incidence of rheumatic fever in an endemic region: a guide to the susceptibility of the population? Epidemiol Infect 2000;24:239-44.

21 Kimbally-Kaky G, Gombet T, Voumbo Y, et al. Les cardiopathies rhumatismales en milieu scolaire à Brazzaville. Med Trop (Mars) 2008:68:603-5.

22 Bergmark R, Bergmark B, Blander J, et al. Burden of disease and barriers to the diagnosis and treatment of group a beta-hemolytic streptococcal pharyngitis for the prevention of rheumatic heart disease in Dar Es Salaam, Tanzania. Pediatr Infect Dis J 2010;29:1135-7.

23 Zühlke L, Engel ME, Karthikeyan G, et al. Characteristics, complications, and gaps in evidence-based interventions in rheumatic heart disease: the Global Rheumatic Heart Disease Registry (the REMEDY study). Eur Heart J 2015;36:1115-22.

24 Mocumbi AO. The challenges of cardiac surgery for African children. Cardiovasc $J$ Afr 2012:23:165-7. 